\title{
BONE MARROW-DERIVED STEM CELLS AS A CYTOTHERAPY FOR SIROLIMUS-INDUCED PERIODONTAL LIGAMENT AND ALVEOLAR BONE INJURY IN A RAT MODEL
}

\author{
Rasha Mohamed Taha* and Heba Abdulfattah Elsaied*
}

\begin{abstract}
Background: Sirolimus is known to be the most common immunosuppressive and anti-cancer drug regardless to its adverse side effects. Bone marrow derived -mesenchymal cells represent a great interest, particularly in the areas of regenerative medicine.
\end{abstract}

Aim of the study: The current research aimed to examine the efficacy of stem cell transplantation for treating the periodontal ligament and alveolar bone affection that caused by Sirolimus.

Materials and methods: Fifty male albino rats with average body weight 200-250 gram were used in this investigation. The animals were divided into the following groups: Group I: 20 rats served as controls and subdivided into 2 subgroups 10 animals each: Group I.1: Using a curved metallic oral gavage, ethanol and saline were given in a daily oral dose of $10 \mathrm{mg} / \mathrm{kg}$ body weight to Group I. 1 for 3 months. Group I.2: treated with the same way as group I.1 then left untreated for 2 weeks Group II: 20 animals subdivided into 2 subgroups, 10 animals each: Group II.1 (Sirolimus group) treated with immunosuppressive drug (Rapamycin) dissolved in ethanol and saline in a daily oral dose of $10 \mathrm{mg} / \mathrm{kg}$ body weight using a curved metallic oral gavage for 3 months. Group II.2: (Recovery group) treated with the same dose and route of administration of group II.1 for 3 months then left untreated for 2 weeks as a recovery period. Group III: 10 rats treated with the same dose of Rapamycin in group II then injected by a single intravenous infusion of mesenchymal bone marrow stem cells. For bone marrow- mesenchymal cells isolation and culture, ten adult male albino rats were used as a source of bone marrow. At the end of experiment, the rats were sacrificed, the jaws of rats were dissected out and processed to be stained with: Hematoxylin and eosin staining for histological examination. Streptavidin-biotin immunohistochemical method for Vimentin and CD44 localization for stem cells characterization and homing detection respectively and streptavidin-biotin immunohistochemical method of $\mathrm{Bcl} 2$ for anti-apoptotic expression detection.

Results: Sirolimus showed dramatic degenerative changes on the periodontal ligaments and alveolar bone, however the transplanted stem cell helped tissues to partially retain their texture and accelerate their healing.

Conclusion Sirolimus caused severe adverse effects on the periodontal ligaments and alveolar bone which did not resolved after recovery period of 2 weeks, however, the degeneration was more dramatic. Interestingly, bone marrow- derived stem cells transplantation represented a promising attempt to overcome the Sirolimus drawbacks.

KEY WORDS: Rapamycin, Bone marrow stem cells, vimentin, Bc12, CD44 


\section{INTRODUCTION}

Sirolimus (also known as Rapamycin) is one of the mammalian target of Rapamycin (mTOR) inhibitors that are classified as immunosuppressor drugs which are approved for solid organ transplantation (SOT) as they inhibit the pathway of ubiquitous mTOR1. Sirolimus, used in kidney-transplant recipient, probably has antineoplastic effects ${ }^{2}$. The rate of carcinoma in transplant recipients of United $\mathrm{Na}$ tions agency treated with Sirolimus were found to be lower than those treated with calcineurin inhibitors either with first-time medical care or once shift ${ }^{3}$.

The immunosuppression ability and antineoplastic effects of Sirolimus may be due to a stander mechanism ${ }^{4}$, Sirolimus inhibits its molecular target (the mammal target of Sirolimus, or mTOR), that integrates signals from the phosphatidylinositol 3-kinase and protein kinase (PI3K/AKT) pathways in order that the growth of proper cells could be regulated through the coordination of ribosomal biogenesis and protein synthesis. The enhancement of mTOR signalling could result in an increase in the expression of the vascular endothelial growth factor which is the key regulator of angiogenesis and lymphangiogenesis ${ }^{5}$. Furthermore, there is another use of the Sirolimus where it is used to treat macrocytic lymphatic malformations, diffuse lymphangiomatosis, and Kaposiform hemangioendothelioma (KHE) with concomitant Kasabach-Merritt phenomenon KMP). ${ }^{6}$

In case of the recipients of kidney graft who had former cutaneous squamous cell carcinoma, the Sirolimus tolerance had a satisfactory antitumoral effect ${ }^{7}$.

When the Rapamycin (mTOR) was introduced in oncology, there were evidence of distinct cutaneous and oral adverse events. As a matter of fact, the most frequent and potentially dose-limiting side effects which were documented are stomatitis and rash. ${ }^{8}$

Compared to the traditional mucositis, the mTOR had oral adverse effects which were more similar to the appearance of aphthous stomatitis. ${ }^{9}$ In addition, the occurrence of the oral symptoms of the targeted therapy, for example rash, xerosis, pruritus, mucosal, and hair abnormalities, reached up to $81 \%$ of patients during treatment with mTORs. ${ }^{10}$ The literature of solid organ transplantation often cites "aphthous-like" oral lesions which have an association with Sirolimus therapy which is used for its immunomodulatory properties ${ }^{11,12}$.

Consistent with the information prescribing the Food and Drug Administration (FDA), Sirolimus may result in increasing individual's risk caused by contracting skin cancers from exposure to sunlight or UV radiation and lymphoma development risk. Under Sirolimus, the risk of skin cancer decreased compared to the case of using under other immunosuppressants including azathioprine and calcineurin inhibitors. Further, it decreased under placebo as well. ${ }^{13}$

The inhibition of mammalian target of Rapamycin complex 1 (mtoRc1) by Sirolimus seems to mitigate the benefits of drug, however it results also it inhibiting mammalian target of Rapamycin complex 2 which in turn causes diabetes-like symptoms including decreasing glucose tolerance and insensitivity to insulin. ${ }^{14}$ In addition, the treatment of Sirolimus could lead to increasing the risk of type 2 diabetes ${ }^{15}$.

The lymphatic complications are considered a common side effect of immunosuppression induced by Sirolimus in kidney transplantation. ${ }^{16}$ The Sirolimus is stated to have high effectiveness in the reduction of lymphatic leakage from microcystic lymphatic malformations involving the skin as well as improving these patients' quality of life ${ }^{17}$.

The stem cells have received so great interest, due to their promising features, as well as their regenerative properties and ability to generate variable-lineage cells. As a result, this has encouraged several studies which provided intriguing perspectives on cell-based therapies for various diseases ${ }^{18}$. 
The idea that the desired effects noticed in the treatment using adult stem cells may be attributed to paracrine effect is supported by studies on animals. ${ }^{19}$ Using various populations of adult stem cells such as bone marrow-derived mononuclear cells (BMMNCs), mesenchymal stem cells (MSCs), and stem cells extracted from cardiac tissue, several clinical trials were carried out. ${ }^{20}$ The marrow of human bones has a small fraction of different populations of stem cells such as hematopoietic stem cells (HSCs), endothelial progenitor cells (EPCs), and Mesenchymal cells (MSCs). Using a Ficoll density gradient centrifugation, such cells could be extracted and then purified to have the final product known commonly as BMMNCs. ${ }^{21}$

Mesenchymal stem cells are characterized by have self-renew power and they are differentiated from the various types of cells. In addition, these cells are most commonly used the therapies of stem cell. $^{22}$

On the other hand, the Mesenchymal stem cells are derived from mesoderm and they are found in various tissues such as the bone marrow (BM), umbilical cord blood, adipose tissues, muscles. ${ }^{18}$ n saphenous veins ${ }^{23}$, dental pulp ${ }^{24}$ and periodontal ligaments..$^{25}$

The biologically similar MSCs which are extracted from various tissue reservoir are still unknown how they are both BM- and non-BM-derived (e.g., adipose tissue) MSCs. However, several tests were conducted on the "pre-conditioned" cardiopoietic MSCs in the studies of cell therapy. ${ }^{26}$

The Mesenchymal stem cells (MSCs) are the most examined types of stem cells due to their unique biological properties of MSCs. ${ }^{27}$ For example, they have the potential of multi-lineage differentiation, they are readily available, and they have extensive capacity in in vitro expansion. Additionally, as these cells secrete trophic factors stimulating the properties of remodelling and immunoregulatory tissues, they are suitable for applications in the treatment of various congenital and acquired diseases ${ }^{28}$.

The ability of MSCs to secrete a wide range of cytokines, chemokines, and growth factors has achieved the benefits of MSC transplants. A large number of studies proposed that the MSCs have a key role in the interaction with their microenvironments which is releasing dozens of active biological ingredients. In turn, such ingredients have great effects on local cellular dynamics ${ }^{29}$. In addition, those studies also showed that such released ingredients may result in the inhibition of adjacent cells from undergoing apoptosis and evoking their proliferation. As a result, this promotes regenerating injured tissue $\mathrm{e}^{30}$.

Studies carried out on both models of humans and animals found that MSCs migrate particularly to the sites of damaged tissues displaying inflammation but they are mostly cornered within the microvasculature of the lung ${ }^{31}$.

It appears that therapies which are based on MSCs will keep the promise of safety and show that the infusion and administration of MSC are well tolerated ${ }^{7}$

\section{MATERIAL AND METHODS}

The current study has received the approval of the Research Ethics Committee, Faculty of Dentistry, Suez Canal University, number 2019/180.

\section{Sample size calculation:}

Sample size calculation was performed using G*Power version 3.1.9.2, Faul et al., (2007), University Kiel, Germany. Copyright (c) 1992-2014².

The effect size was 0.65 using alpha $(\alpha)$ level of 0.05 and Beta $(\beta)$ level of 0.05 , i.e., power $=95 \%$; the estimated minimum sample size (n) was a total of $\mathbf{5 0}$ samples for Five groups.

\section{Grouping:}

Fifty male albino rats with average body weight 200-250 gram were used in this investigation. 
The animals were divided into the following groups:

Group I: 20 rats served as controls and subdivided into 2 subgroups 10 animals each:

Group I.1: Received ethanol and saline in a daily oral dose of $10 \mathrm{mg} / \mathrm{kg}$ body weight using a curved metallic oral gavage for 3 months.

Group I.2: Treated with the same way as group I.1 then left untreated for 2 weeks

Group II: 20 animals subdivided into 2 subgroups, 10 animals each:

Group II.1 (Sirolimus group) treated with immunosuppressive drug (Rapamycin) dissolved in ethanol and saline in a daily oral dose of $10 \mathrm{mg} / \mathrm{kg}$ body weight using a curved metallic oral gavage for 3 months ${ }^{29}$.

Group II.2: (Recovery group) treated with the same dose and route of administration of group II.1 for 3 months then left untreated for 2 weeks as a recovery period.

Rapamycin (Sirolimus) was supplied in tablet form (1 gram), from Sigma Chemical Company; USA, that were ground into powder and dissolved in ethanol to concentration of $0.1 \mathrm{mg} / \mathrm{ml}$ and the diluted with saline to final concentration of $0.5 \mathrm{mg} / \mathrm{ml}$.

Group III (Stem cell treated group): 10 rats treated with the same dose of Rapamycin in group II then injected by a single intravenous infusion of mesenchymal bone marrow stem cells ${ }^{30}$.

The animals were caged, five animals per cage and labelled according to their group, they were maintained under optimum conditions of good ventilation and temperature. Animals were supplied natural diet and drinking tap water adlibitum. The experimental work of this study was performed in the animal house of faculty of dentistry, Suez Canal University.

The percentage of mortality for each group were calculated and recorded, gross examination of head and neck of each animal was carried out through the whole experimental period.

At the end of experiment which lasted 2 months for group I.1, and II.1 and 2 months and 2 weeks for group I.2, II.2 and III, rats were sacrificed by a cotton soaked with a lethal dose of diethyl ether inside a closed glass container, the jaws of rats were dissected out (for periodontal ligaments and alveolar bone investigation). Then, specimens were collected and immersed in $10 \%$ formalin after 2448 hours they were put in 10\% EDTA ( $\mathrm{pH} 7.4$ ) - for bone decalcification- and the solution was changed every week for 3-5 weeks. The specimens were washed in (phosphate buffered saline) PBS and then embedded in paraffin. The embedding process was carried out by immersion in $70 \%, 80 \%, 96 \%$ ethanol (90 minutes each), three immersions in absolute ethanol (60 minutes each), two immersions in xylol (90 minutes each) and two immersions in liquid paraffin at $60^{\circ} \mathrm{C}(120$ minutes each). Finally, sections of $5 \mu \mathrm{m}$ thickness were obtained with a microtome and placed on adhesive-coated glass slides. Six microns thick sections were cut to be stained with:

1. Hematoxylin and eosin staining for histological examination.

2. Streptavidin-biotin immunohistochemical method for Vimentin localization for stem cells characterization.

3. Streptavidin-biotin immunohistochemical method for CD44 localization for stem cells homing detection.

4. Streptavidin Immunohistochemical methods for Bcl2 localization for anti-apoptotic expression detection.

\section{BM-MSCs isolation and culture:}

Animals: Ten adult male albino rats were used as a source of bone marrow; weighing 200-250 grams each and aged 6 months. Before the use, the study followed all the applicable institutional and national guidelines for the care and use of laboratory animal. 
The laboratory work was performed in the tissue culture lab of centre of excellence of molecular and cellular medicine (CEMCM), Suez Canal University.

Under complete aseptic condition both femur and tibia from each rat were excised. Careful anterior dislocation of the femur took place to get its head out of the acetabulum to keep the medullary cavity closed and guard against infection. The adherent flesh was removed carefully. Both ends of each bone were cut, and the bone marrow was harvested by flushing with $10 \mathrm{ml}$ syringe with Dulbecco Modified Eagle Medium (DMEM) (Sigma-Aldrich) (Fig 1). After washing and centrifugation at 1800 rpm for 10 minutes, cell pellet was collected and cultured in a $75-\mathrm{cm}^{2}$ flask in a DMEM medium supplemented by $10 \%$ foetal bovine serum (FBS, Gibco) and $1 \%$ penicillin and streptomycin $(\mathrm{P} / \mathrm{S}$; volume /volume) (Sigma-Aldrich). The cultures were incubated at $37 \mathrm{oC}$ with $5 \% \mathrm{CO} 2$ and saturated humidity. The first culture media was changed after 24 hours to remove non-adherent cells and the adherent cells were cultured and passaged to expand the MSCs population. The subsequent medium exchange was performed every 3-5 days till the cultures approximately $80-90 \%$ confluence $^{32}$. MSCs population were examined under inverted microscopes.

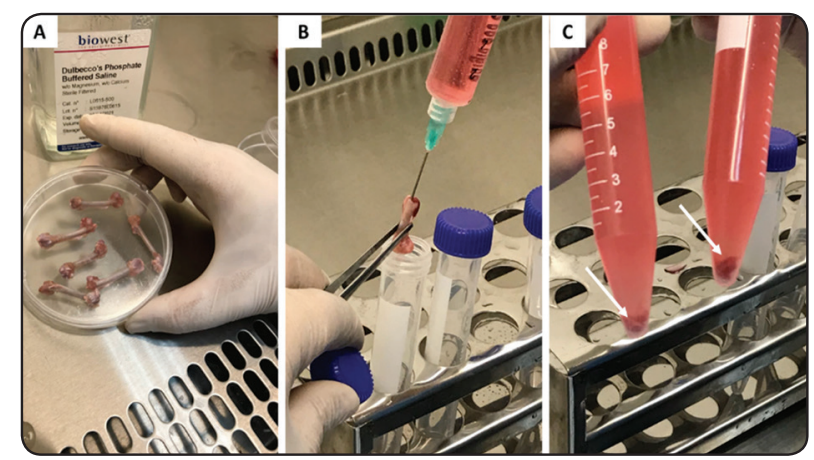

Fig. (1) Photomicrographs showing steps of rat bone marrow harvesting. A: femurs and tibiae of rat after removing the covering flesh with intact both bone ends. B: flushing the opened medullary cavity with DMEM. C: cell pellet (arrow) after washing and centrifugation of the bone marrow cell suspension.

\section{Subculturing of BM-MSCs:}

The adherent cells were washed twice with phosphate buffer saline (PBS, Biowest) to get rid of any traces of the complete media. A suitable amount of $0.25 \%$ trypsin (Gibco) was added to each flask to form a thin film over the cultured cells for 5-10 minutes at $37^{\circ} \mathrm{C}$ after which the enzyme was inactivated with same amount of complete culture media. Centrifugation and supernatant discarding took place. The cells pellet of each flask was resuspended in complete media and divided into 2 or 3 new flasks according to their number. Using haemocytometer, the BM-MSCs were passaged two times and counted at each passage and assessed regarding their viability.

\section{AD-MSCs transplantation:}

A dose of $2 \times 10^{6} \mathrm{BM}-\mathrm{MSC}$ was suspended into $0.5 \mathrm{ml}$ DMEM and injected intravenously in the tail vein, over 2 minutes ${ }^{32}$, of group III animals that treated with Rapamycin drug dissolved in ethanol and saline daily in an oral dose of $10 \mathrm{mg} / \mathrm{kg}$ body weight (Fig.2).

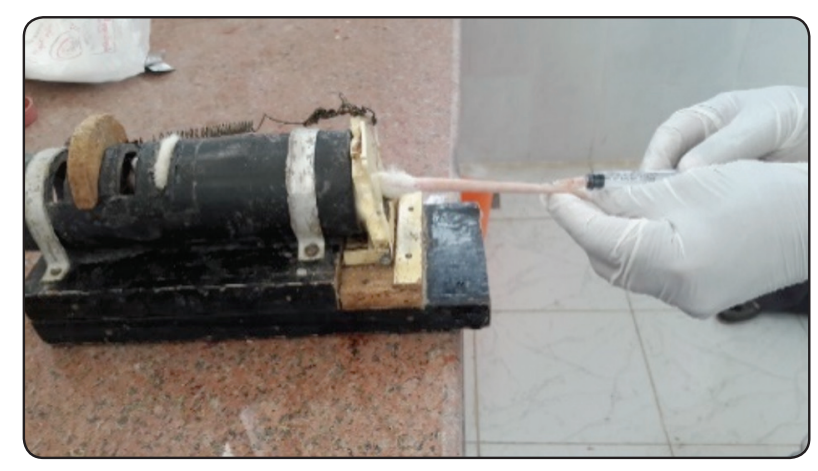

Fig. (2) A photograph showing intravenous injection of bone marrow stem cells in the tail vein of rat

\section{Immunohistochemical method used for detection of (Vimentin, CD44, BCL2):}

The immunohistochemical detection system used is ultravision mouse tissue detection system: Antimouse HRP/DAB which is brought together with primary antibody (mouse monoclonal antibody of Vimentin, CD44, and BCL2). 
The labelled streptavidin-biotin immune-enzymatic antigen detection system is represented in the kit by the regents where such technique contains the sequential incubation of the section characterized by an unconjugated primary antibody which is specific to the targeted antigen. The targeted antigen is a biotinylated secondary antibody which has a reaction with the primary antibody enzyme called "streptavidin and DAB chromogen".

To evaluate the proliferation of positive immunoreactivity for vimentin, CD44 and Bcl 2 in the periodontal ligaments and bone, an ordinary light microscope was used. Then, the optical density of vimentin, $\mathrm{CD} 44$ and $\mathrm{Bcl} 2$ positive cells and the intensity of the immunostaining were assessed using the J Image analyser computerized system.

\section{Statistical analysis:}

\section{Experimental design and data analysis}

All data were calculated, tabulated and statistically analyzed using suitable statistical tests as follows:

A normality test was done to check normal distribution of the sample, and all groups and subgroups showed normal distributions.

Descriptive data: Descriptive statistics were calculated in the form of Mean \pm Standard deviation (SD), range (Max- Min), median, Coefficient of variance (C.V \%).

Results were statistically analyzed by SPSS version 22 (SPSS Inc., Chikago, IL, USA). ANOVA (F test) was used for analyzing data. Post hoc test was used after one a way ANOVA (F test) or Kruskal -Wallis test to show any significant difference between the individual groups. In case the value of $\mathrm{p}<0.05$, it is considered significant.

\section{RESULTS}

\section{Cell culture results:}

Bone marrow cells of primary culture at day 3 after seeding, were examined under inverted microscope, they were allocated into two cell population; rounded floating cells and attached cells to the substratum of the tissue culture flask. The floating cells were discarded with the $1^{\text {st }}$ media exchange. The attached cells were few in number at this time, fibroblast-like in shape with fine cytoplasmic processes (Fig. 3 A). Small cell colonies were evident from the $3^{\text {rd }}$ day after seeding (Fig. 3 B) the cells of which overlapping each other and in a higher magnification the cells appeared with abundant nuclei with multiple nucleoli (Fig. 3C). The colonies exhibited larger size by the $5^{\text {th }}$ day (Fig. 3 D) and the cells reached 90\% confluence by the $10^{\text {th }}$ day after seeding (Fig. $3 \mathbf{~ E}$ ).

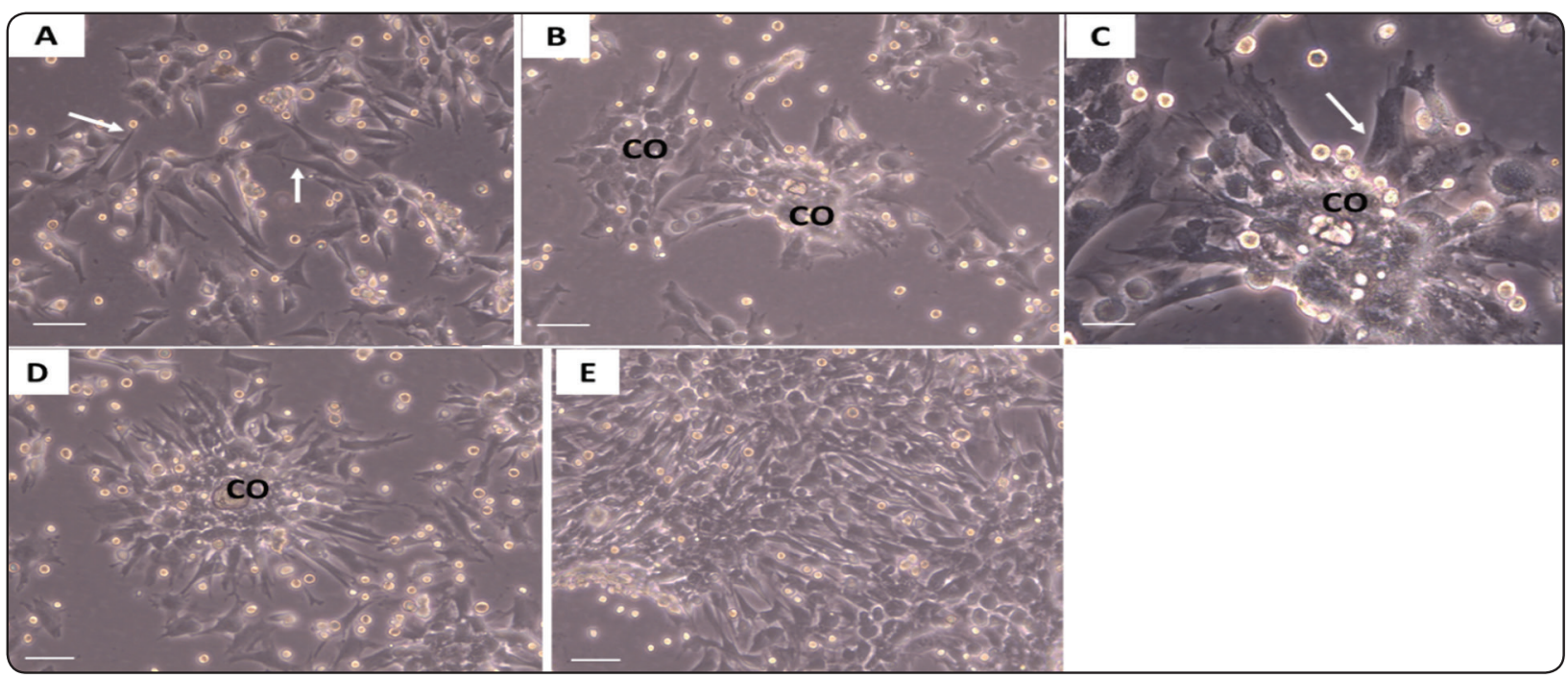

Fig. (3) Phase contrast photomicrograph of rat BM-MSCs. A: attached fibroblast-like cells with fine cytoplasmic processes (arrow) 3 days post seeding. B: small sized colonies $(\mathrm{CO})$ at day $3 \mathbf{C}$ : a higher magnification of $\mathbf{B}$ showing multi-layered colonies. The cells appear with large nuclei possessing multiple nucleoli. D: larger colonies (CO) at day 5. E: the cultured cells reached about $90 \%$ confluence at day 10.A, B, D \& E; scale bar $(20 \mu$ X100). C; (scale bar $50 \mu$ X200.). 


\section{Percentage of mortality:}

Percentage of mortality of rats of both control and treated groups was $0 \%$.

\section{Light microscopic results:}

Control group: examination of group I.1 that received ethanol and saline in a daily oral dose of $10 \mathrm{mg} / \mathrm{kg}$ body weight using a curved metallic oral gavage for 3 months and group I.2 that treated with the same way as group I.1 then left untreated for 2 weeks showed normal histological picture of periodontal ligaments (PDL) and alveolar bone.

- The periodontal ligament of the control groups (I.1, I.2) rats composed of cells, fibers, blood vessels \& nerves. The collagen fibers which are the main components of the PDL were composed of the gingival group of fibers attached to the cervical part of the cementum and extended to the free and attached gingiva, where they fused with the lamina propria of the gingiva. The interdental or trans-septal group of fibers were extending from the cementum of one tooth to the cementum of adjacent tooth crossing above the crest of the alveolar bone. The alveolo-dental group of fibers attached to the cementum from one side and to the alveolar bone on the other side and were subdivided into: alveolar crest fibers, horizontal, oblique, apical and inter-radicular fibers. Cells of the PDL were predominantly fibroblasts, progenitor cells and some of the defensive cells were seen. Interstitial spaces between the bundles of fibers were demonstrated having blood vessels and alveolar connective tissue.

- The attachment epithelium appeared normal mostly attached to the cervical part of the crown with no massive apical migration

- The alveolar bone appeared normal, consisted of alveolar bone proper and reinforced alveolar bone. The alveolar bone proper forming the inner walls of the sockets and containing the openings of Zuckerkandl and Hirschfeld canals were formed of bundle bone and lamellar bone. Sharpey's fibers were inserted in the bundle bone, which are the part of the alveolar bone proper forming the inner most walls of the socket. Adjacent to it, the lamellar bone was found where the lamellae were arranged either parallel to each other or in the form of Haversian systems. The supporting alveolar bone composed of spongiosa and cortical plates of compact bone. The alveolar bone showed normal turnover rate, as the number of the reversal lines were minimal. Besides, the PDL/ bone interface appeared to be smooth; no osteoclastic activity was observed. Fig. 4 (A,B,C,D).

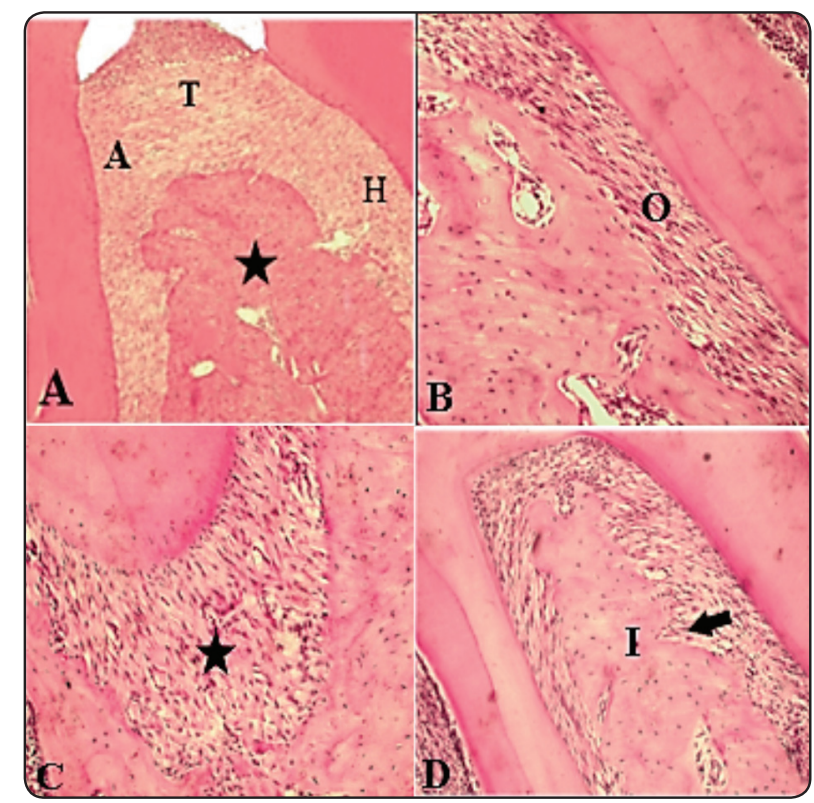

Fig. (4) A photomicrograph of control group (I.1, I.2) showing (A) gingival, transseptal (T) alveolar crest (A) and horizontal $(\mathrm{H})$ periodontal ligaments principle fibers. Interseptal bone (star). (B) Oblique principle fibers of periodontal ligaments (O). (C) Apical principle fibers (star) of periodontal ligaments. (D) Interradicular fibers and interradicular bone (I) and Zuckerkandl and Hirschfeld canals (arrow). (Mag. X 200, 400, 400,200).

Group II. 1 (Sirolimus group): examination of periodontal ligaments of rats treated with 
immunosuppressive drug (Rapamycin) dissolved in ethanol and saline in a daily oral dose of $10 \mathrm{mg} /$ $\mathrm{kg}$ body weight using a curved metallic oral gavage for 3 months showed detachment and dissociation of the principle fibers, marked dilatation of blood vessels, a lot of Howship's lacuna and osteoclasts on the surface of the bone, widening of the marrow cavities with fibrotic contents \& inflammatory cells infiltrate, thinning of bone trabeculation and widening of Zuckerkandl and Hirschfeld canals. Attachment epithelium showed no apical migration but vacuolization and thickening of its epithelium. Fig 5 (A, B, C, D).

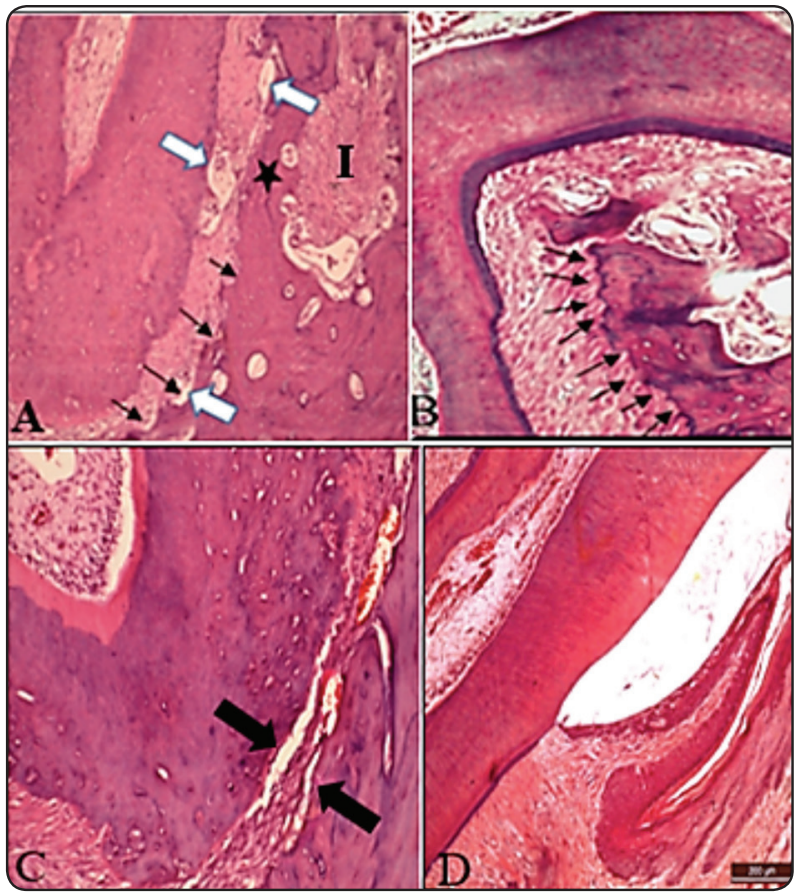

Fig. (5) A photomicrograph of group II.1 showing (A) marked dissociation of oblique fibers with focal areas of detachment of fibers from the alveolar bone and cementum (white arrows), a lot of Howship's lacunae (black arrows), thinning of bone trabeculae of alveolar process (star), widening of the marrow cavities with fibrotic contents \& inflammatory cells infiltrate (I). (B) Interradicular fibre of periodontal ligaments showing dissociation and osteoclastic activity on the interradicular bone (arrows). (C) Apical fibers with detachments from alveolar bone and cementum sides (black arrows), marked dilatation of blood vessel engorged with RBCs (D) attachment epithelium showing vacuolization and thickening of its epithelium with no apical migration (Mag. X, 200, 400, 400, 200).

\section{Group II. 2 (Recovery group)}

Examination of periodontal ligaments and alveolar bone of rats treated with immunosuppressive drug (Rapamycin) dissolved in ethanol and saline in a daily oral dose of $10 \mathrm{mg} / \mathrm{kg}$ body weight using a curved metallic oral gavage for 3 months then left 2 weeks for recovery showed detachment and massive dissociation of the principle fibers, marked dilatation of blood vessels and haemorrhage, a lot of Howship's lacuna and osteoclastic activity on the bone surfaces, widening of the marrow cavities with degradable contents, thinning of bone trabeculation and widening of Zuckerkandl and Hirschfeld canals. Attachment epithelium showed no apical migration but vacuolization and thickening of its epithelium, with massive dissociation of underlying connective tissue and dilated blood vessels and haemorrhage. Fig 6

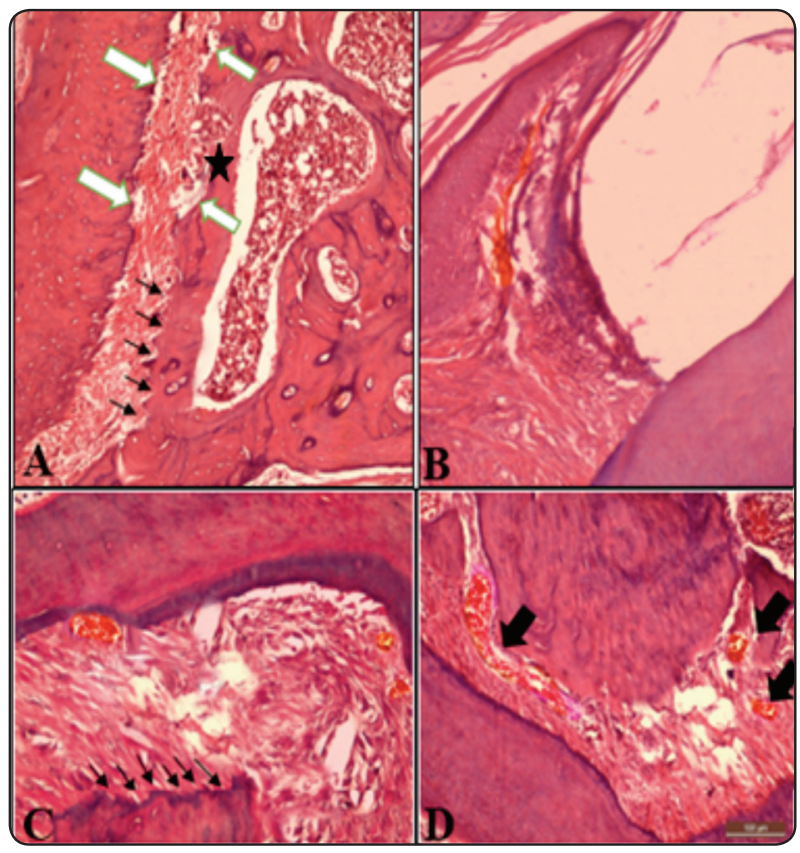

Fig. (6) A photomicrograph of the periodontal ligaments and alveolar bone of recovery group showing (A) dissociation of oblique fibers, with detachment from the bone and tooth side (White arrows) widening of marrow cavity and thinning of bone trabeculae. Howship's lacunae in the bone surface (black arrows). Widening of zuckerkandl and Hirschfeld canals (B) Attachment epithelium with marked connective tissue dissociation and large dilated blood vessels engorged with RBCs. (C) Interradicular fiber with focal area of detachment from tooth side and Howship's lacunae in the interradicular bone (Arrows) and dilated blood vessels (D) Dissociation of apical fiber with dilated blood vessel engorged with RBCs (Arrows). (Mag. X 200, 200, 400, and 400). 
Group III: Examination of the periodontal ligaments of rats treated with the same dose of Rapamycin in group II then injected by a single intravenous infusion of mesenchymal bone marrow stem cells showed partial improvements, mostly in the arrangement and association of the fibers of PDL. Compared to recovery group, the fibers mostly regained their arrangement and association together in bundles, as dissociation of fibers and disorientation were at minimum in this group of animals. Dilatation of the blood vessels was still observed, however in lesser degree compared to recovery group animals. A lot of empty Howship's lacunae were observed on the bone side. Bone also showed a lot of reversal lines. The marrow cavity appeared almost normal. Zuckerkandl and Hirschfeld canals showed widening with blood vessels dilatation. The epithelium attachment had no apical migration but thickening and some vacuolization in its surface epithelium.

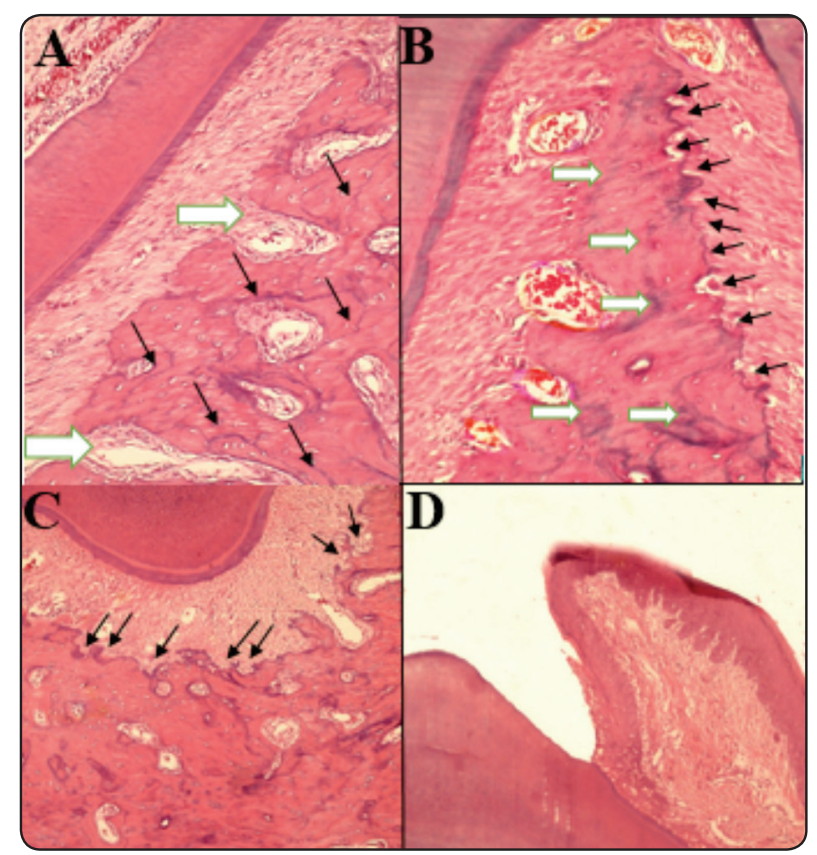

Fig. (7) A photomicrograph of group III showed (A) Almost normal oblique fibers with widening of Zuckerkandl and Hirschfeld (white arrow) canal. Bone showing number of reversal lines (Black arrow). (B) Normal interradicular and oblique fibers with dilated blood vessels, the interradicular bone showing a lot Howship's lacunae (Black arrows) and number of reversal lines (White arrows). (C) Normal apical fibers with dilated blood vessels and the bone showing a lot of Howship's lacunae (arrows) and normal marrow cavities. (D) Almost normal attachment epithelium unless thickening it is epithelium thickness (Mag. X 400,400, 200, and 200).

\section{Immunohistochemical results:}

\section{Immunohistochemical localization of Vimentin for stem cell characterization}

Group I.1 and I.2 (control groups): Control groups (I.1, I.2) showed moderate immunoreactivity staining to Vimentin for both periodontal ligaments and alveolar bone cells. Group II: Both Group II.1 (Sirolimus group) and II.2 (recovery group) showed mild immunoreactivity staining to vimentin for both periodontal ligaments and bone cells. Group III: showed severe immunoreactivity staining to vimentin (Fig. 8).

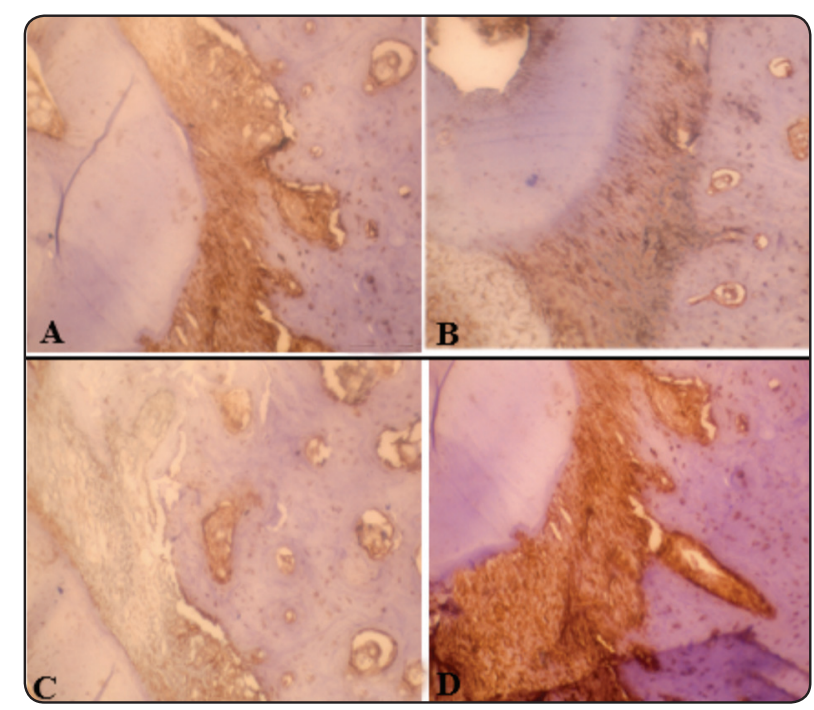

Fig. (8) A photomicrograph of the periodontal ligament and bone group incubated with mouse monoclonal antibody of vimentin from (A) control group (I.1, I.2) showing moderate immunostaining reactivity of the periodontal ligaments and bone cells. (B) Group II.1 (Sirolimus group) showing mild immunostaining reactivity of the periodontal ligaments and bone cells. (C) Group II.2 (recovery group) showing mild immunostaining reactivity of the periodontal ligaments and bone cells. (D) Group III showing severe immunostaining reactivity of the periodontal ligaments and bone cells. (Mag. X 400). 


\section{Immunohistochemical localization of CD44 for stem cells homing detection:}

Control groups (I.1, I.2) showed moderate immunoreactivity staining to CD44 for both periodontal ligaments and alveolar bone cells. Group II: Both groups II.1 (Sirolimus group) and II.2 (recovery group) showed mild immunoreactivity staining toCD44 for both periodontal ligaments and bone cells. Group III: showed severe immunoreactivity staining to CD44. Fig.9

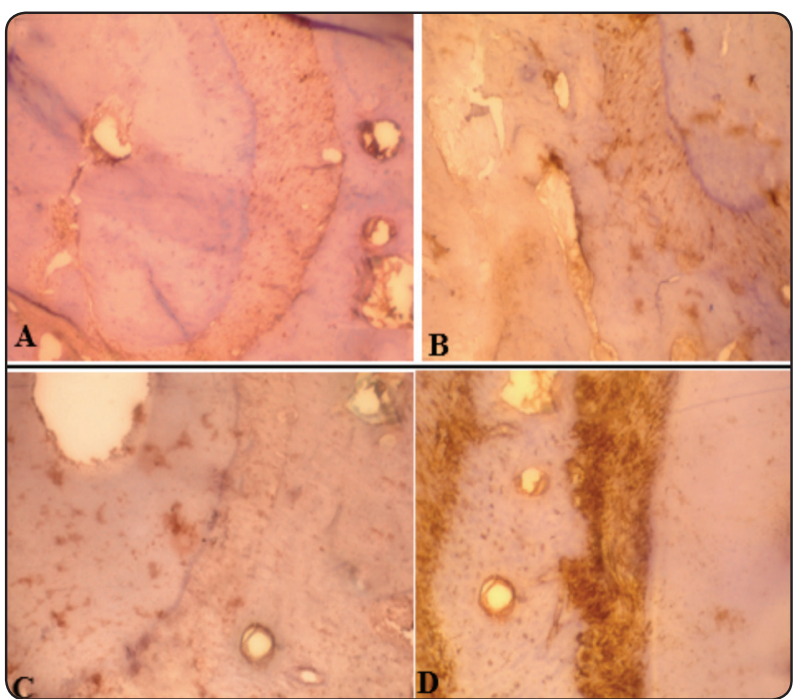

Fig. (9) A photomicrograph of the periodontal ligament and bone group incubated with mouse monoclonal antibody of CD44 from (A) Control group (I.1, I.2) showing moderate immunostaining reactivity of the periodontal ligaments and bone cells. (B) Group II.1 (Sirolimus group) mild immunostaining reactivity of the periodontal ligaments and bone cells (C) Group II.2 (Recovery group) mild immunostaining reactivity of the periodontal ligaments and bone cells. (D) Group III severe immunostaining reactivity of the periodontal ligaments and bone cells. (Mag. X400).

\section{Immunohistochemical localization of Bcl2 for apoptotic activity detection:}

\section{Group I.1 and I.2 (control groups):}

Control groups (I.1, I.2) showed mild immunoreactivity staining to $\mathrm{Bcl} 2$ for both periodontal ligaments and alveolar bone cells.
Group II: Both Group II.1 (Sirolimus group) and II.2 (recovery group) showed severe immunoreactivity staining to Bcl2 for both periodontal ligaments and bone cells. Group III: showed moderate immunoreactivity staining to Bcl2. Fig. 10

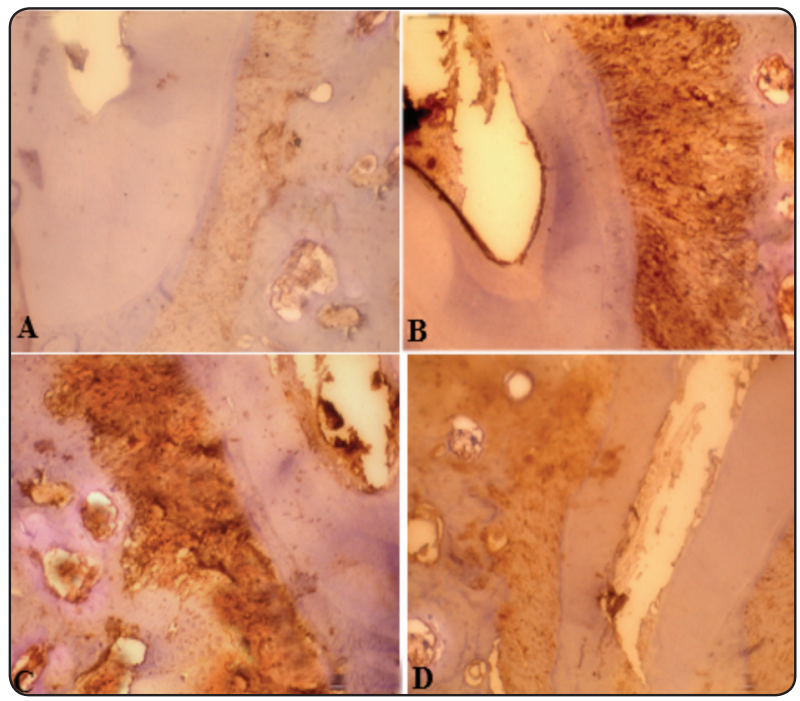

Fig. (10) A photomicrograph of the periodontal ligament and bone incubated with mouse monoclonal antibody of Bcl2 from (A) from Control groups (I.1, I.2) showing mild immunostaining reactivity of the periodontal ligaments and bone cells to Bcl2 (B) Group II. 1 (Sirolimus group) showing severe immunostaining reactivity of the periodontal ligaments and bone cells to Bcl2 (C) Group II.2 (Recovery group) showing severe immunostaining reactivity of the periodontal ligaments and bone cells to Bcl2 (D) Group III showing moderate immunostaining reactivity of the periodontal ligaments and bone cells to Bcl2. (Mag. X 400).

\section{Statistical analysis:}

Results were statistically analyzed by SPSS version 22(SPSS Inc., Chicago, IL, USA). ANOVA (F test) was used for analyzing data. After one a way ANOVA (F test), a Post hoc test was carried out to identify whether there is any significant difference between the individual groups.

Regarding to Vimentin, the results in table (1) showed significant difference between groups for periodontal ligaments (P.L) and alveolar bone at $\mathrm{P}$ value $(\mathrm{P} \leq 0.05)$. Group III gave the highest values followed by control group (I.2, I.1) for P.L 
and alveolar bone with value 116.22, 114.49 and $90.08,88.32$ respectively, on the other hand the II. 2 (Recovery) group had the lowest values for these variables. (Figure 11).

TABLE (1) Showing the significant difference in vimentin immunoreactivity between different groups for periodontal ligaments and alveolar bone.

\begin{tabular}{|c|c|c|}
\hline \multicolumn{3}{|c|}{ Vimentin } \\
\hline Groups & P.L. & alveolar bone \\
\hline Control group (I.1) & $88.96^{\mathrm{b}} \pm 2.28$ & $87.76^{\mathrm{b}} \pm 2.75$ \\
\hline Control Group ( I.2) & $90.08^{b} \pm 1.19$ & $88.32^{b} \pm 3.44$ \\
\hline Group II.1 (Sirolimus) & $76.35^{\mathrm{c}} \pm 3.28$ & $75.00^{c} \pm 3.57$ \\
\hline Group II.2 (Recovery) & $68.62^{\mathrm{d}} \pm 2.25$ & $67.13^{\mathrm{d}} \pm 3.27$ \\
\hline $\begin{array}{l}\text { Group III (Stem cell } \\
\text { treated) }\end{array}$ & $116.22^{\mathrm{a}} \pm 1.63$ & $114.49^{\mathrm{a}} \pm 2.65$ \\
\hline $\mathrm{p}$ value $(\mathrm{P} \leq 0.05)$ & $0.000 * * *$ & $0.000 * *$ \\
\hline $\begin{array}{l}* *, a, b \text { means signi } \\
\text { significant levels }(P\end{array}$ & different & en groups at \\
\hline
\end{tabular}

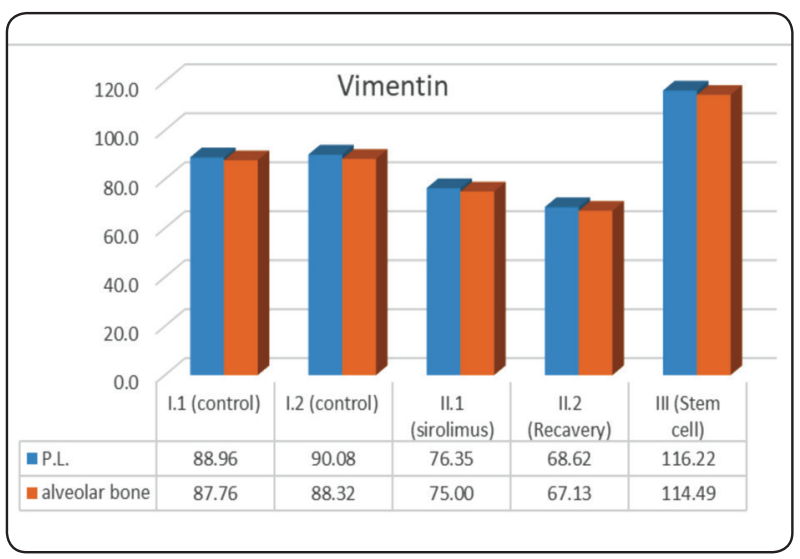

Fig.(11) A double- bar graph represents difference in the mean vimentin optical density between different group for periodontal ligaments and alveolar bone.

Concerning to CD44, the results in table (2) showed significant difference between groups for P.L and alveolar bone at $\mathrm{P}$ value $(\mathrm{P} \leq 0.05)$. The control group I.1 and I.2 and Stem cell showed none significant between them and gave the highest value for P.L and alveolar bone while the Sirolimus and recovery showed the lowest values for the same variables. (Figure 12)

TABLE (2) Showing the significant difference in CD44 immunoreactivity between different groups for periodontal ligaments and alveolar bone.

\begin{tabular}{|c|c|c|}
\hline \multicolumn{3}{|c|}{ CD44 } \\
\hline Groups & P.L. & alveolar bone \\
\hline Control group ( I.1) & $100.30^{\mathrm{a}} \pm 2.08$ & $99.50^{\mathrm{a}} \pm 5.09$ \\
\hline Control Group ( I.2) & $99.23^{\mathrm{a}} \pm 1.45$ & $98.76^{\mathrm{a}} \pm 2.04$ \\
\hline Group II.1 (Sirolimus) & $67.80^{\mathrm{b}} \pm 2.00$ & $66.19^{b} \pm 3.10$ \\
\hline Group II.2 (Recovery) & $50.98^{c} \pm 3.16$ & $49.14^{c} \pm 4.56$ \\
\hline Group III (Stem cell treated) & $99.37^{\mathrm{a}} \pm 1.49$ & $97.01^{\mathrm{a}} \pm 3.56$ \\
\hline $\mathrm{p}$ value $(\mathrm{P} \leq 0.05)$ & $0.000 * * *$ & $0.000 * *$ \\
\hline $\begin{array}{l}* *,{ }^{a, b} \text { means significa } \\
\text { significant levels }(P \leq 0.0\end{array}$ & 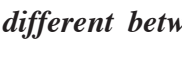 & ups at \\
\hline
\end{tabular}

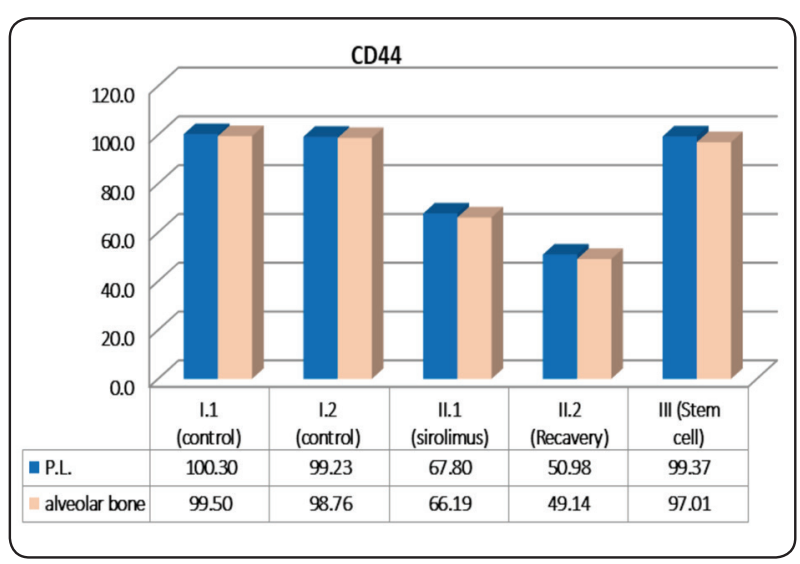

Fig.(12) A double- bar graph represents difference in the mean CD44 optical density between different group for periodontal ligaments and alveolar bone.

Concerning to BLC2, the results in table (3) showed significant difference between groups for P.L and alveolar bone at $\mathrm{P}$ value $(\mathrm{P} \leq 0.05)$. The recovery group gave the highest value followed by Sirolimus group for P.L and alveolar bone with value $108.0,102.73$ and $106.74,101.14$ respectively (figure 13). 
TABLE (3) Showing the significant difference in $\mathrm{Bcl} 2$ immunoreactivity between different groups for periodontal ligaments and alveolar bone.

\begin{tabular}{|c|c|c|}
\hline \multicolumn{3}{|c|}{ Table (3) BLC2 } \\
\hline Groups & P.L. & alveolar bone \\
\hline Control group ( I.1) & $73.08^{\mathrm{d}} \pm 3.28$ & $72.64^{c} \pm 8.73$ \\
\hline Control Group ( I.2) & $73.05^{\mathrm{d}} \pm 3.29$ & $70.10^{c} \pm 2.83$ \\
\hline Group II.1 (Sirolimus) & $102.73^{\mathrm{b}} \pm 2.12$ & $101.14^{\mathrm{a}} \pm 2.10$ \\
\hline Group II.2 (Recovery) & $108.00^{\mathrm{a}} \pm 2.36$ & $106.74 \mathrm{a} \pm 2.67$ \\
\hline Group III (Stem cell treated) & $87.86^{c} \pm 2.83$ & $86.84^{\mathrm{b}} \pm 4.59$ \\
\hline $\mathrm{p}$ value $(\mathrm{P} \leq 0.05)$ & $0.000 * *$ & $0.000 * *$ \\
\hline $\begin{array}{l}* *,{ }^{a, b} \text { means signific } \\
\text { significant levels }(P \leq 0\end{array}$ & lifferent & en groups at \\
\hline
\end{tabular}

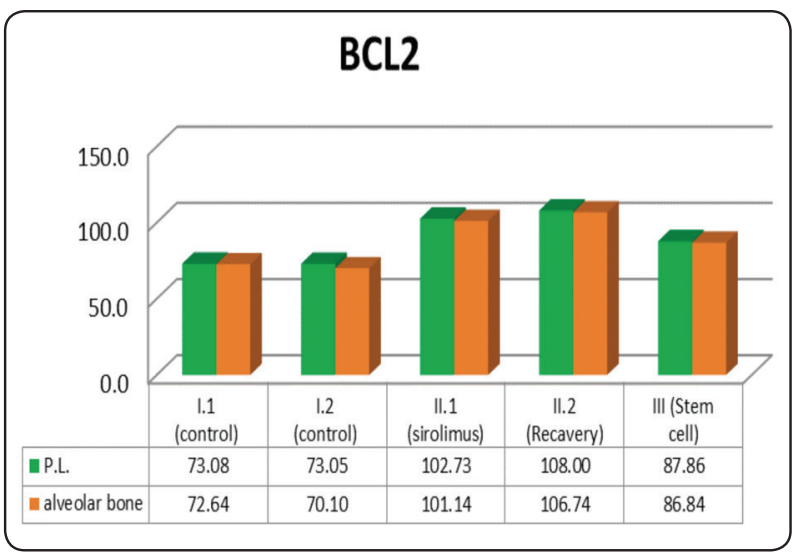

Fig.(13) A double- bar graph represents difference in the mean $\mathrm{Bcl} 2$ optical density between different group for periodontal ligaments and alveolar bone.

\section{DISCUSSION}

The Sirolimus is considered as a mammalian target of Rapamycin (mTOR) inhibitors. The Rapamycin (mTOR) inhibitors are perceived as targeted chemotherapeutic treatments of cancer and as a post-transplantation immunosuppressive. The chemotherapeutic treatments of cancer have several side effects, especially when they are used the oral cavity, as such serious lesions may result in reducing the dose or stopping the anticancer treatment completely. As a result, in order to ensure the efficiency of cancer treatments, these disabling and painful lesions should be managed. ${ }^{33}$

The early immunosuppressive agents had a key shortcoming which is the lack of specificity. Further, as the immune cell function and replication were widely suppressed, there were serious toxicities and several negative effects ${ }^{34}$. A disequilibrium of the inflammatory cytokine balance in transplanted patients is triggered by Sirolimus resulting in a paradoxical inflammatory response with mild stochastic clinical symptoms in the weeks after the introduction of the drug. In turn, such pathophysiologic mechanism leads to unifying the different individual inflammatory side effects which are frequently observed with Sirolimus. In addition, it leads to the suggestion that it is necessary to perceive them as a single syndromic entity ${ }^{35}$.

Accordingly, the objectives of this research were to evaluate the injurious effects of Sirolimus on the periodontal ligament and alveolar bone in a rat model and the alleviation of these effects by transplantation of bone marrow-derived stem cells as a cytotherapy.

In the current study, light microscopic examination of periodontal ligaments of rats treated with immunosuppressive drug (Rapamycin) dissolved in ethanol and saline in a daily oral dose of $10 \mathrm{mg} /$ $\mathrm{kg}$ body weight using a curved metallic oral gavage for 3 months showed detachment and dissociation of the principle fibers. Zheng et al., 2018 gave an explanation to our results as Rapamycin inhibits fibroblast proliferation and collagen accumulation possibly through inhibition of Transforming growth factor $\beta 1$ (TGF- $\beta 1$ ) signalling. The authors added that Rapamycin stimulates autophagy, reduced collagen synthesis, and suppressed myofibroblast activation $^{36}$, which gave an explanation of the degenerative effects of Rapamycin on the principle fibers. Dilatation of blood vessels in the periodontal ligaments was a marked notice after Sirolimus treatment. This result was explained by Aboujaoude and Milgrom, 2004 who demonstrated that 
prostaglandins release stimulation by Sirolimus, which may result in an increase in vasodilatation or in lymphatic leakage in certain vascular segments. ${ }^{37}$

In current investigation, changes occurred on the bone was represented by a lot of Howship's lacunae and osteoclasts on the surface of the bone, thinning of bone trabeculation, widening of Zuckerkandl and Hirschfeld canals, widening of the marrow cavities that appeared mostly fibrotic and infiltrated with inflammatory cells. The dramatic changes encountered in the alveolar bone of the Sirolimus group rats could be due to Rapamycin effect on bone metabolism, it can reduce osteogenic differentiation of human bone marrow stromal cells (BMSCs) and osteoblasts (MG63 cells) by inhibiting mTOR signaling ${ }^{38}$. Basal and bone morphogenic protein-7 (BMP-7) which is induced by the osteogenic marker expression and bone nodule mineralization in foetal rat calvarial cells can be inhibited by Rapamycin ${ }^{39}$. Rapamycin produced cortical bone osteopenia to normal rats when used as monotherapy ${ }^{40}$.

The histological examination of the periodontal ligaments and alveolar bone of recovery group (group II.2) showed aggravation of the degenerative changes encountered in the Sirolimus group this means that Sirolimus administration stoppage for 2 weeks as recovery period didn't help the tissues of this study to be restored, however more tissue degeneration occurred.

Nicotinamide adenine dinucleotide (NAD) requires a tightly controlled balance between synthesis and degradation of this dinucleotide within the cell. In addition, it is used as a co-substrate for enzymes which generate signalling metabolites or modify protein substrates post-translationally. The resultant signalling networks which are dependent on NAD can modify the dynamics of chromatin and transcription factor and the kinetics of numerous enzymes in order to match the physiological responses with the circadian rhythms and feeding status.$^{41}$ Consequently, localized restrictions in the bioavailability of NAD may have potential profound effects on the functions of cells by dampening such signals or having the production of ATP impaired. In addition, these restrictions were observed during genotoxic stress states accompanying an increasing list of diseases such as cancer and neurodegeneration, and the course of natural aging. ${ }^{42}$ The previous researches could explain aggravation of degeneration of recovery group.

Attachment epithelium showed increase in thickness and vacuolization in its epithelial thickness with no apical migration in both group II (Sirolimus and recovery group). In vitro experiments Rapamycin resulted in a decrease in the proliferation of cells and an increase in the number of cells which were arrested in $\mathrm{G}_{0} / \mathrm{G}_{1}$ phase ${ }^{43}$. Consequently, according previous study, the epithelium turnover and homeostasis disrupted led to increase in its thickness with signs of apoptosis and cell death that represented by vacuolization.

Many research works have proved the regenerative effects of stem cells which made the stem cells as rich source for therapeutic uses in many disorders as in cardiovascular system disorders where the stem cells showed outstanding results in regenerating heart tissues, ${ }^{44}$ in metabolic disorders, ${ }^{45}$ in neurological disorders and in many other tissues. ${ }^{46}$

There is a wide acceptance of the fact that MSCs have a mediation effect of tissue repair and such effect is generated by secreting trophic factors, specifically exosomes. MSC exosomes enhanced regeneration through increased cellular mobilisation and proliferation ${ }^{47}$.

Examination of the periodontal ligaments of rats treated with the same dose of Rapamycin in group II then injected by a single intravenous infusion of mesenchymal bone marrow stem cells showed partial improvements, mostly in the arrangement and dissociation of the fibers of PDL indicating that mesenchymal stem cells which are represented by a potential therapeutics to treat periodontal defects. These findings are consistent with those of 
Kimura et al., 2014 who found that BMSCs migrate to the periodontal tissue defects. Including a subset of MSCs, the employment of BMSCs represents a new target of periodontal treatment ${ }^{48}$.

One of the studies which separated the BMSCs of humans and mice found RANK expressions in vitro and in vivo. Following the beginning of the osteogenic differentiation, the RANK expression was quickly down regulated. Interestingly, there was no effect of the RANK expression during the adipogenic differentiation. As a result, the study suggested that RANK may function in regulating osteoblastic differentiation. ${ }^{49}$ Several factors such as cytokines have the ability to evoke the BMSCs to differentiate into osteoblasts.

Bone morphogenic proteins (BMPs) are considered the most important cytokines. ${ }^{50}$ Among a number of factors which may lead to activating or inhibiting the osteoblastic signaling pathways, the BMP is considered a key regulating factor to differentiate BMSCs into osteoblasts. Furthermore, the differentiation of BMSCs into osteoblasts can be enhanced by the increased BMP contents. ${ }^{51}$

Using human bone morphogenetic protein 2 (hBMP2) in order to incubate the in vitro cultures of BMSCs, Ishikawa et al, 2007 showed that the hBMP-2 reinforced the proliferation of cells. However, it kept the osteogenic differentiation in the passaging process ${ }^{52}$. This might explain the marked improvement in the alveolar bone following injecting rats with a single intravenous infusion of mesenchymal bone marrow stem cells.

One of the most noticeable results of this study was vasodilatation of blood vessels, soluble mediators which are released into the extracellular matrix and correct the dysfunction of endothelial progenitor are generated by $\mathrm{MSC}^{53}$. Vasodilation in group III may be a trial to improve the blood flow.

In the current study, immunohistochemical localization of Vimentin for stem cells characterization: showed significant difference between groups for P.L and alveolar bone at $\mathrm{P}$ value $(\mathrm{P} \leq 0.05)$. The stem cell group gave the highest values followed by group I.2 (control) for P.L and alveolar bone, on the other hand group II.2 (Recovery) had the lowest values for these variables.

These results indicated that the isolated and transplanted cells are genuine, non-hematopoietic marrow stromal cells have stem cell like characteristics. Accordingly, they were mostly present in the stem cell group. Also, stem cells were characterized in the control groups as the oral cavity is well known a fairly rich source of MSCs with osteogenic potential; stem cells can be naturally found in the dental pulp, dental follicle, dental apical papilla, periodontal ligament and gingiva. Proliferation and bone regeneration capacity is different among these cell types ${ }^{54}$.

The findings of current study are on agreement with those of bone marrow samples which are collected from 10 rats and produced 4-5 million bone marrow mononuclear cells $/ \mathrm{ml}$ per femur. Using the combined method (the combination of Ficoll density gradient centrifugation and plastic adherence) to obtain the cells, a high percentage of positivity for vimentin, fibronectin and CD90 and negative for hematopoietic markers was found. In turn, this indicates that following the simple principle of adhesion, an efficient method of harvesting a fairly homogenous population of bone marrow stromal cells can be possibly established. In addition, it is shown that the phenotypic characteristics and differential potential of these cells refer to the stem cell like features..$^{55}$

Concerning to CD44, our results showed significant difference between groups for P.L and alveolar bone at $\mathrm{P}$ value $(\mathrm{P} \leq 0.05)$. The control group ( I and II) and stem cell group showed none significant difference between them and gave the highest value for P.L and alveolar bone while the Sirolimus and recovery groups showed the lowest values for the same variables. 
Expression of stem/progenitor cell marker CD44 is one of the stem cells features which plays an important role in maintaining the mesenchymal phenotype. Other features include repression of the expression of E-cadherin and induction of the expression of mesenchymal genes, like vimentin and N-cadherin ${ }^{56}$.

Consequently, we could conclude that the recruited BMCs had the greatest residence in P.L and alveolar bone of the control group (I.1 and I.2) and group (III) stem cell group followed by the Sirolimus and recovery groups.

CD44, CD90 (markers which are associated with stromal cells) are expressed by PDL-MSCs but the specific markers for identifying PDL-MSCs are still uncovered and the lack of such markers results in limiting their precise isolation and characterization. ${ }^{57}$

From pervious data we suggested that Sirolimus drug might affect the stem cells present naturally in the periodontal ligaments and bone marrow as it showed lowest records in Sirolimus and recovery group, while transplanted stem cells in group III reached the degenerated tissues of PDL and alveolar bone which proved by the high records of Vimentin and helped in regeneration of the degeneration occurred due to Sirolimus administration.

Concerning to BLC2, the results showed significant difference between groups for P.L and alveolar bone at $\mathrm{P}$ value $(\mathrm{P} \leq 0.05)$. The recovery group gave the highest value followed by Sirolimus group for P.L and alveolar bone with value.

Apoptosis is considered a very important process which has an effect on the normal development and tissue homeostasis and the Apoptotic proteins including bcl-2 and Bax proteins help to regulate the apoptosis. In addition, the Bcl-2 is used as antiapoptotic protein, whereas the Bax is used as a proapoptotic protein, and the balance between such proteins helps to determine the apoptotic process ${ }^{58}$.

An integral role is played by the BCL-2 family members in apoptosis, however they also have a contribution to several other cellular functions. Of all the BCL-2 family members, Isoforms is identified and some of them are well described. The therapeutics which targets BCL-2 indicates a great promise of treating cancer and degenerative diseases..$^{59}$

Yang et al., 2018 reported that the treatment of Sirolimus results in a significant decrease in Bax expression, caspase- 3 , caspase- 8 , and caspase- 9 in response to ureteral obstruction, but it results in an increase in Bcl-2 expression. ${ }^{60}$ Moreover, Liu et al., 2013 showed that Rapamycin leads to an increase in the activated form of Cyclic-AMP response element-binding protein (pCREB), Bcl-2, and vascular endothelial growth factor A (VEGF-A) via regulation of extracellular signal-regulated kinases (ERK) under normoxia ${ }^{61}$. These results came inconsistent with the results of this study as the bcl2 increased significantly in recovery group and also showed significance difference in the Sirolimus treated rats due to Sirolimus dramatic effects on the bone and periodontal ligaments and attempts of these tissues to survive. unlikely, in group treated with stem cells after Sirolimus administration there was decreasing in bcl2 expression comparing to Sirolimus group, that indicate our histological results as there was noticeable improvement of tissues this of investigation and partially restore their normal texture.

Consequently, this study suggested that Sirolimus causing sever adverse effects on the periodontal ligaments and alveolar bone, which not resolved after recovery period of 2 weeks however the degeneration was more dramatic. While after BMCs injection, partial improvement is occurred and the tissues start to retain their normal textures which indicate the protective role of BMCs and its ability to accelerate tissues healing. Interestingly, bone marrow- derived stem cells transplantation represented a promising attempt to overcome the Sirolimus drawbacks. 


\section{REFERENCES}

1. Ventura-Aguiar P, Campistol JM and Diekmann F. Safety of mTOR inhibitors in adult solid organ transplantation. Expert Opin Drug Saf. 15:303-319, 2016.

2. Schena FP, Pascoe MD, Alberu J, et al. Conversion from calcineurin inhibitors to Sirolimus maintenance therapy in renal allograft recipients: 24-month efficacy and safety results from the convert trial. Transplantation. 87:233-242, 2009.

3. Stallone G. Schena A. Infante B. Di Paolo S. Loverre Antonella. Maggio G. Ranieri E. Gesualdo L. Schena F P. and Grandaliano G. Sirolimus for Kaposi's Sarcoma in Renal-Transplant Recipients. N Engl J Med. 352:1317$1323,2005$.

4. Lee DF and Hung MC.All roads lead to mTOR: integrating inflammation and tumor angiogenesis. Cell Cycle. 6:30113014, 2007.

5. Hammill AM, Wentzel M, Gupta A. Sirolimus for the treatment of complicated vascular anomalies in children. Pediatr Blood Cancer. 57:1018-1024, 2011

6. Dantal J, Morelon E and Rostaing L.Sirolimus for Secondary Prevention of Skin Cancer in Kidney Transplant Recipients: 5-Year Results. Journal of Clinical Oncology. 36:2612-2620, 2018

7. Squillaro T. Peluso G, and Galderisi U. Clinical Trials With Mesenchymal Stem Cells: An Update. Cell Transplantation. 25: 829-848, 2016.

8. Lee WJ, Lee JL and Chang SE. Cutaneous adverse effects in patients treated with the multitargeted kinase inhibitors sorafenib and sunitinib. Br J Dermatol. 161:1045-1051, 2009.

9. Sonis S, Treister $\mathrm{N}$ and Chawla S. Preliminary characterization of oral lesions associated with inhibitors of mammalian target of Rapamycin in cancer patients. Cancer. 116:210 -215, 2010.

10. Lee WJ, Lee JL, Chang SE. Cutaneous adverse effects in patients treated with the multitargeted kinase inhibitors sorafenib and sunitini. Br J Dermatol; 161:1045-1051, 2009.

11. Mahe E, Morelon E and Lechaton S. Hanh Sang K., Mansouri R, ;Marie- Ducasse F., Mamzer-Bruneel M., de Prost Y., Kreis H. and Bodemer C.:Cutaneous adverse events in renal transplant recipients receiving Sirolimusbased therapy. Transplantation. 79:476-482, 2005.

12. Boers-Doets CB, Raber-Durlacher J E and Treister N S. Mammalian target of Rapamycin inhibitor-associated stomatitis. Future Oncol. 9: 1883-1892, 2013.
13. Euvrard S, Morelon E, Rostaing L, Goffin E, Brocard A, Tromme I, Broeders N, del Marmol V, Chatelet V, Dompmartin A, Kessler M, Serra AL, Hofbauer GF, Pouteil-Noble C, Campistol JM, Kanitakis J, Roux AS, Decullier E, Dantal J. "Sirolimus and secondary skincancer prevention in kidney transplantation". The New England Journal of Medicine. 367: 329-39, 2012

14. Lamming DW, Ye L, Katajisto P, Goncalves MD, Saitoh M, Stevens DM, Davis JG, Salmon AB, Richardson A, Ahima RS, Guertin DA, Sabatini DM and Baur JA. "Rapamycininduced insulin resistance is mediated by mTORC2 loss and uncoupled from longevity". Science. 335: 1638-1643, 2012.

15. Arriola Apelo SI, Neuman JC, Baar EL, Syed FA, Cummings NE, Brar HK, Pumper CP, Kimple ME, Lamming DW. "Alternative rapamycin treatment regimens mitigate the impact of rapamycin on glucose homeostasis and the immune system". Aging Cell. 15: 28-38, 2016

16. Huber S., Bruns J., and Hermann SC. Inhibition of the mammalian target of Rapamycin impedes lymphangiogenesi. Kidney International. Elsevier; 71: 771-777, 2007.

17. Jochen Rössler MD, Julia Geiger MD, Etelka Földi MD. Sirolimus is highly effective for lymph leakage in microcystic lymphatic malformations with skin involvemen. International journal of dermatology. 56:72$75,2017$.

18. Stempien-Otero A, Helterline $\mathrm{D}$ and Plummer $\mathrm{T}$. Mechanisms of bone marrow-derived cell therapy in ischemic cardiomyopathy with left ventricular assist device bridge to transplant. Journal of the American College of Cardiology. 65:1424-1434, 2015.

19. Nguyen P K., Wha Rhee J and Wu J C. Adult stem cell therapy and heart failure, 2000 to 2016: a systematic review. JAMA Cardiol. 1: 831-841, 2016.

20. Bianco P, Riminucci M, Gronthos S, Robey PG. Bone marrow stromal stem cells: nature, biology, and potential applications. Stem Cells. 19:180-192, 2001.

21. Yen-Shun C. Yi-An C., Pei-Hsun T. Chih-Ping C., Sheng W. and Yogi H. Mesenchymal Stem Cell: Considerations for Manufacturing and Clinical Trials on Cell Therapy Product. Int J Stem Cell Res Ther. 3:1-12; 2015

22. Williams AR and Hare JM. "Mesenchymal stem cells: biology, pathophysiology, translational findings, and therapeutic implications for cardiac disease". Circulation Research. 109:923-940, 2011 
23. Gullo F. and De Bari C. Prospective purification of a subpopulation of human synovial mesenchymal stem cells with enhanced chondro-osteogenic potenc. Rheumatology (Oxford). 52:1758-1768, 2013.

24. Covas D. T., Piccinato C. E., Orellana and Siufi M. D. Mesenchymal stem cells can be obtained from the human saphena vei. Exp. Cell. Res. 309:340-344, 2005.

25. Perry, B. C., Zhou, D., Wu, X. Yang, F. C., Byers M. A. and Chu, T. M. et al. Collection, cryopreservation, and characterization of human dental pulp-derived mesenchymal stem cells for banking and clinical us. Tissue Eng. Part C Methods. 14:149-156, 2008.

26. Montesinos J. J., Mora-Garcia Mde L. and Mayani, Het al. "In vitro evidence of the presence of mesenchymal stromal cells in cervical cancer and their role in protecting cancer cells from cytotoxic T cell activit. Stem Cells Dev. 22:2508-2519, 2013.

27. Gao LR, Chen Y and Zhang NK. Intracoronary infusion of Wharton's jelly-derived mesenchymal stem cells in acute myocardial infarction: double-blind, randomized controlled trial. BMC Medicine. 13:162-176, 2015.

28. Wang S., Qu X. and Zhao, R. C. Clinical applications of mesenchymal stem cells. J. Hematol. Oncol. 5:19-25, 2012 .

29. Alexander R. Guimaraes, Robert Ross and Jose L. "MRI with Magnetic Nanoparticles Monitors Downstream AntiAngiogenic Effects of mTOR Inhibition". Mol Imaging Biol. 13:314-320, 2011.

30. Wang J., Liao L. and Tan J. Mesenchymal-stem-cell-based experimental and clinical trials: Current status and open questions. Expert Opin. Biol. Ther. 11:893-909, 2011.

31. Yoshimatsu G., Sakata N. and Tsuchiya H. The Co-Transplantation of Bone Marrow Derived Mesenchymal Stem Cells Reduced Inflammation in Intramuscular Islet Transplantation. PLoS One. 10:1-18, 2015.

32. Faul F., Erdfelder E., Lang, A.-G., and Buchner, A. G Power 3: A flexible statistical power analysis program for the social, behavioral, and biomedical sciences. Behavior Research Method. 39: 175-191, 2007.

33. Zhou $1 \mathrm{H}$. and Huang S. Current development of the second generation of mTOR inhibitors as anticancer agents. Chin J Cancer. 31: 8-18, 2012

34. Calvo A S. Rochefort J. Javelot M. J., Descroix V. and Lescaille G. Management of mTOR inhibitors oral mucositis: current state of knowledge. J Oral Med Oral Surg; 25:11, 2019.
35. Zdanowicz M. M, The Pharmacology of Immunosuppression Am J Pharm Educ. 73: 144, 2009

36. Zheng W, Qian Y., Chen S., Ruan H. and Fan C. Rapamycin Protects Against Peritendinous Fibrosis Through Activation of Autophagy. Front Pharmacol 9: 1-15, 2018.

37. Aboujaoude, W.; Milgrom, M. L; Govani, M. V. Lymphedema Associated With Sirolimus In Renal Transplant Recipient. Clinical Transplantation. 77: 1094-1096, 2004.

38. Asher G and Sassone-Corsi P. Time for food: the intimate interplay between nutrition, metabolism, and the circadian clock. Cell. 161:84-92, 2015.

39. Cantó C, Menzies KJ and Auwerx J. NAD(+) Metabolism and the Control of Energy Homeostasis: A Balancing Act between Mitochondria and the Nucleus. Cell Metab. 22:31-53, 2015.

40. Faghihi, F., Baghaban, E. M., Nekookar, A., Najar, M., and Salekdeh, G. H. The effect of purmorphamine and sirolimus on osteogenic differentiation of human bone marrow-derived mesenchymal stem cell. Biomedicine and Pharmacotherapy. 67:31-38, 2013.

41. Yeh, L. C., Ma, X., Ford, J. J., Adamo, M. L., and Lee, J. C. Rapamycin inhibits BMP-7-induced osteogenic and lipogenic marker expressions in fetal rat calvarial cells. Journal of Cellular Biochemistry. 114: 1760-1771, 2013.

42. Ruber M. t, Montero M., and Guede D. Sirolimus and tacrolimus rather than cyclosporine A cause bone loss in healthy adult male rats. Bone Rep. 2: 74-81, 2015.

43. Wang Y, Xu W., Yan Z., Zhao W., Mi J., Li J. and Yan H. Metformin induces autophagy and G0/G1 phase cell cycle arrest in myeloma by targeting the AMPK/mTORC1 and mTORC2 pathways. J Exp Clin Cancer Res. 37: 63-75, 2018.

44. Fu D., Yin J., Huang S. , Li H., Li Z. and Chong T. . Rapamycin Inhibits the Growth and Collagen Production of Fibroblasts Derived from Human Urethral Scar Tissue. Biomed Res Int. 2018: 785-1327, 2018

45. Couzin J., Clinicla trials: A shot of bone marrow can help the heart.science; 313:1715-1716, 2006.

46. Hebrok M.: Generating $\beta$-cells from stem cells. Cold spring Harb Perspect Med.; 2:674-675, 2012.

47. Perrier AL., Tabar V., Barberi T., Rubio M E., and Bruses J.: Derivation of midbrain dapamine neurons from human embryonic stem cells. Proc Natl Acad Sci U.S.A. 19:12543-12548, 2004.

48. Kimura Y., Komaki M., Iwasaki K., Sata M., Izumi Y. and Morita I. . Recruitment of bone marrow-derived cells to periodontal tissue defects. Front Cell Dev Biol. 2: 19-27, 2014. 
49. Chen X., Zhi X, Wang J. \& Su J.. RANKL signaling in bone marrow mesenchymal stem cells negatively regulates osteoblastic bone formation Bone Research. 6: 34-45, 2018.

50. Toh W S., Lai R. C., Zhang B., and Lim S. K. MSC exosome works through a protein-based mechanism of action Biochem Soc Trans. 46: 843-853, 2018.

51. Wei F, Zhou Y, Wang J, Liu C and Xiao Y: The immunomodulatory role of BMP-2 on macrophages to accelerate osteogenesis. Tissue Eng Part A. 24:584-594, 2018.

52. Ishikawa $H$, Kitoh H, Sugiura $F$ and Ishiguro N: The effect of recombinant human bone morphogenetic protein- 2 on the osteogenic potential of rat mesenchymal stem cells after several passages. Acta Orthop. 78:285-292. 2007.

53. Kenneth M. Fish and Roger J. Hajjar: Mesenchymal Stem Cells \& Endothelial Function. EBioMedicine. 2: 376-377, 2015.

54. Buduru S. D., Gulei D. , Zimta A., Tigu A B., Cenariu D., Berindan-Neagoe A. Cells. The Potential of Different Origin Stem Cells in Modulating Oral Bone Regeneration Processes. 8: 29-39, 2019

55. Polisetti N., Chaitanya V., Babu P. P. and Vemuganti G.K. characterization and differentiation potential of rat bone marrow stromal cells. Isolation. 58:201-208, 2010.
56. Fontana F., Raimondi M., Marzagalli O. M. Sommariva M., Limonta P. and Gagliano N. Epithelial-To-Mesenchymal Transition Markers and CD44 Isoforms Are Differently Expressed in 2D and 3D Cell Cultures of Prostate Cancer Cells. Cells. 8: 143-149, 2019.

57. Tomokiyo A. Yoshida S., Hamano S., Hasegawa D., Sugii H. and Hidefumi Maeda. Detection, Characterization, and Clinical Application of Mesenchymal Stem Cells in Periodontal Ligament Tissue. Stem Cells Int.; 2018:1-17, 2018.

58. Gokalp-Ozkorkmaz E., Kirman G., Pekkolay Z., Asir F. and Deveci E. Expression of Apoptotic Proteins Bax and Bcl-2 in Blood Cells of Type 2 Diabetic Patient. 2: 1563 $1570,2018$.

59. Chloe F A. Warren, Michelle W. Wong-Brown and Nikola A. Bowden BCL-2 family isoforms in apoptosis and cancer. Cell Death \& Disease. 10: 177- 190, 2019.

60. Yang M., Zhuang Y., Wang W.,1 Zhu H., Zhang Y., Zheng S., Yang Y., Chen B., Xia P. and Zhang Y. Role of Sirolimus in renal tubular apoptosis in response to unilateral ureteral obstruction. Int J Med Sci. 15: 1433-1442, 2018.

61. Liu Y, Zheng Q., Wu H., Guo X., Li J. and Hao S. Rapamycin increases pCREB, Bcl-2, and VEGF-A through ERK under normoxia. Acta Biochim Biophys. 45: 259-267, 2013. 